\title{
The Influence of Pre-existing Deformation on GMA Welding Distortion in Thin Steel Plates
}

C. M. Davies ${ }^{1}$, J. Ahn $^{1^{*}}$, M. Tsunori ${ }^{2}$, D Dye ${ }^{3}$ and K. M. Nikbin ${ }^{1}$

${ }^{1}$ Department of Mechanical Engineering, Imperial College London, South Kensington Campus, London SW7 2AZ

${ }^{2}$ Ishikawajima-Harima Heavy Industries Co. Ltd, Shin-Nakahara-Cho, Isogo-ku, Yokohama, 2358501, Japan

${ }^{3}$ Department of Materials, Imperial College London, South Kensington Campus, London SW7 2AZ

\section{Abstract}

Weld distortion is particularly problematic for large thin structures that are used in the assembly of ships. The drive towards lighter ships and thinner plate is restricted by the significant increase in distortion as the plate thickness decreases. The influence of pre-existing deformation in the plates to be joined on the resultant distortion in gas metal arc (GMA) welded structure has been studied. DH-36 steel plate surface profiles were measured before and after the butt welding of two plates $1000 \times 500 \times 4 \mathrm{~mm}$ in size. Three dimensional finite element (FE) models that incorporate the initial plate profile have been created to simulate the welding process and to examine the relationship between the final welded plate profiles and the initial deformation present in the plates. Both symmetric and asymmetric models were considered. A significant variation in the unwelded base plates' initial distortion was observed. Generally, it has been found that if an out-of-plane deformation exists in a plate prior to welding, the level of distortion further increases in the same direction following welding. The final distortions are strongly related to the initial plate profiles. The residual stress distributions in the plates are also to some extent affected by the level of distortion initially present.

\section{Keywords}

Welding Simulation; DH-36 Steel; Distortion; Residual Stress

*corresponding author: joseph.ahn08@imperial.ac.uk; Tel: 020759 47035; Fax: 02075947017 


\section{Introduction}

Ship structures typically consist of panels constructed by the gas metal arc welding (GMAW) of large, thin plates. Typically these are butt welded with the subsequent addition of fillet welded stiffeners, and the plates range in size from $4 \times 2 \mathrm{~m}$ to $12 \times 3 \mathrm{~m}$. Current trends are to minimize plate thicknesses to as little as $4 \mathrm{~mm}$, enabling a lightweight and hence high speed vessel. The use of thin plates however leads to large distortions, which in turn present difficulties in panel assembly and lead to high rectification costs. Significant variability in the distortion profiles obtained under industrial conditions is typically observed, which suggests that if the causes of distortion could be determined and controlled then the introduction of thinner plates could be achieved without incurring excessive rework costs.

Finite element models for welding have been developed over many years [1-3]; good predictions for residual stresses can routinely be obtained in materials where transformation plasticity is not a concern and where the heat source has been correctly calibrated. However, distortion predictions have proved more difficult, although for idealised situations where restraint is not a concern good predictions can also be obtained, providing that appropriate element types are used [4]. The advantage of a model-based approach is that the sensitivity of the predictions to changes in parameters, such as welding process conditions, restraint and so forth can be examined in isolation.

It is widely recognised that initial distortions in addition to a range of other factors including residual stresses, can significantly influence a structure's compressive strength and resistance to buckling distortion. Pre-existing deformations (or imperfections) are generally included in models to predict a structure's compressive strength (see e.g. [5]) and the influence of the initial distortion profile in addition to its maximum amplitude on post-weld distortion and buckling strength may be considerable [6]. However, the influence of residual stresses is often not considered or a simple residual stress distribution is assumed to avoid the computational effort required to model the actual residual stress distribution [7, 8]. 
Very few detailed studies have been performed that consider the influence of initial distortion profiles on the prediction of weld induced residual stress and distortion. The experimental variability in distortions between a set of ten panels welded under nominally identical conditions has been examined in [9], and the differences observed attributed to the initial pre-existing deformation in the plates. In [9] the post tack-welding distortion profile of a thin plate was measured and incorporated into numerical methods to predict the post-weld distortion profile, where it was found that, for the single case considered, the inclusion of pre-existing deformation is important to describe the final distortion profile. The influence of boundary conditions on the out-of-plane deformation has also been examined in $[10,11]$, leading to a viable strategy for the modelling of restraint, but the initial plate profile was not considered.

In this work, a finite element model is developed for GMAW of thin, low alloy steel plates and is used to examine the influence of the initial distortion present in the plates, in addition to the effects of tack welding, on the subsequent residual stress distributions and distortion profiles. A large number of experiments have been performed to examine and quantify the variability of post weld distortion profiles of plates welded under similar conditions, as reported in e.g. [12]. However, since there are a number of factors that influence the final distortion, e.g. distortion is highly sensitive to heat input which will have a natural variability in manual GMAW, the distinct influence of preexisting deformation cannot be clearly determined from experimental studies. Hence, a deterministic study is required, as performed here, to examine the influence on pre-existing deformation on distortion predictions, in addition to the influence of small variations in heat inputs that represent actual conditions. The results of the finite element models are compared to the distortions and residual stresses actually measured in the plates, where the thermal model was calibrated with experimental data. Predictions based on the pre-tack welded, post-tack welded and initially undeformed plate profiles have been obtained to establish the predictions sensitivity to the initial profile. 


\section{Experimental Description and Observations}

Rolled sheets $4 \mathrm{~mm}$ in thickness, made of $\mathrm{DH}-36$ high strength low alloy steel, were laser cut to form plates measuring $1000 \times 500 \mathrm{~mm}$. The welds were fabricated by GMAW using NST MC-1 [13] weld wire chosen to over-match the plate's yield strength. The nominal compositions of the DH-36 steel plate and weld wire are shown in Table 1. The plates being joined were held $4 \mathrm{~mm}$ apart by a series of four tack welds which were located at both ends and approximately $330 \mathrm{~mm}$ from each end (see Figure 1). During the welding process the plates were rested (unrestrained) on strips of ceramic backing tile to prevent conduction into the welding table, simplifying the thermal boundary conditions in weld simulations. A single pass weld was made in each case, opposing the rolling direction.

The two typical distortion modes in a butt welded plate are illustrated in Figure 2 i.e. angular distortion resulting from bending around the weld axis and the longitudinal bending around the axes transverse to the weld. The angular distortion can be quantified as the angle, $\alpha$, subtended by each half of the plate, and the longitudinal bending (camber distortion) by the maximum deviation along the weld length from the flat profile, $\hat{z}$, and also by an average radius of curvature, $R$.

Two plates are considered, denoted Plate 1 and Plate 2, which consisted of two original sides, a and $\mathrm{b}$. The welding parameters for both plates are given in Table 2. The plates' profiles were measured initially prior to welding, after tack welding and after welding and cool-down to room temperature. Temperatures were monitored during the welding process by Type $\mathrm{K}$ thermocouples attached over a range of distances from the weld centre at the mid length of the plate.

Multi station convergent photogrammetry was employed to quantify the distortion in the plates. This technique requires a network of intersecting images for the identification of common points within those images and is calibrated using coded targets with known positions. Reflective targets were attached to the plates (see Figure 1) and 16 images taken from different locations around the plates. The imagery was processed using the software 'Vision Metrology Systems' [15]. 


\subsection{Initial Plate Profiles}

Contour plots illustrating the measured plates profile initially, after tack welding and after butt welding are shown in Figure 3. The weld centre is at $x=0$ and the welding direction runs in the positive $y$ direction $(y=0 \rightarrow 1000 \mathrm{~mm})$. The plates' edges to be welded are shown at $x= \pm 2 \mathrm{~mm}$; negative $x$ values correspond to the plate side denoted 'a' and positive $x$ values to side ' $b$ '. On average a precision of $0.01 \mathrm{~mm}$ was achieved in the $x, y$ and $z$ for all targets [16]. A linear interpolation has been made for the plates' co-ordinates between the measurement positions. Since measurements could not be obtained in the weld region itself, a linear gradient has been assumed between the weld and the nearest measurement position, hence the plates profile towards the welded edge is not precisely represented and some potential for extrapolation error exists.

Plates $1 \mathrm{a}$ and $1 \mathrm{~b}$ had similar initial profiles. Both plates $1 \mathrm{a}$ and $1 \mathrm{~b}$ had negative (downwards) distortions near the middle of the plates and positive distortions towards the corners. However, there was a relatively larger distortion of up to $9.8 \mathrm{~mm}$ at the top right hand corner of plate $1 \mathrm{~b} . \mathrm{A}$ large distortion of over $9 \mathrm{~mm}$ was also measured in plate 2a but no significant region of negative distortion was observed. In comparison, a relatively little $(<2 \mathrm{~mm}$ over the majority of the plate) distortion was found in plate $2 \mathrm{~b}$. Overall it is clear that the initial distortion in plates $1 \mathrm{a}$ and $\mathrm{b}$ was around twice as large as in plates $2 a$ and $b$. These distortions, which are maximum at the plate edges result from the relaxation of residual stresses during laser cutting large rolled as-received sheets to the required plate dimensions (see e.g. $[17,18]$ ). The initial curvature, $R$, and maximum deviation, $\hat{z}$ of all plates are quantified in Table 3 .

Similar deformation modes are observed in the post tack welding profile measurements of both Plate 1 and Plate 2, Figure 3(c, d); the largest distortion is exhibited at tack $2(y=1000 \mathrm{~mm})$ and slightly negative $(>-1 \mathrm{~mm})$ at the plates edges, close to their mid length. The tack weld procedure increased the distortion compared to that of the initial base plates, whilst accommodating the misfit between both plates being joined. The resultant profiles of the plates are relatively symmetrical. 
The camber distortion along the edges of all plates, prior to and after welding, is further illustrated in Figure 4. The camber distortion at the edge of the plates was very similar after tacking, Figure 4(b), especially for plate 1 though some asymmetry exists between both sides of plate 2 . In general tacking appears to average out the overall camber distortion in the two sides.

The post weld distortions measured in Plate 1 and Plate 2 are shown in Figure 3(e) and (f), respectively. Different modes of deformation were measured in the two plates. For Plate 1 , the peak displacement and resultant distortion is at the weld start position, whereas for Plate 2 the peak displacement at the plate's edge and close to its mid length; Plate 1 took up a 'U'-shaped distortion mode, contrasting with the 'N' shaped model in Plate 2.

\section{Weld Simulation Model}

Sequentially coupled thermal-mechanical finite element simulations of the welding process were implemented using ABAQUS [19]. Two types of three dimensional (3D) models have been constructed, a half model where symmetry conditions are assumed at the weld centre line and a full model which allows for asymmetric conditions.

Firstly, the initial profile (prior to tack welding) based on the measurements from side $a$ and $b$ of Plate 1 and Plate 2 was used to generate four separate symmetric models of initially distorted meshes, denoted Plate $1 \mathrm{a}, 1 \mathrm{~b}, 2 \mathrm{a}$ and $2 \mathrm{~b}$. In addition a fifth symmetric model, denoted Plate $\mathrm{U}$, was developed which was initially flat and hence contains no initial distortion. The influence of variations in the initial distortion profiles has therefore been examined by performing a finite element weld simulation on these five symmetric plates using identical welding parameters.

Analyses have then been performed on full sized plate models, thus allowing for asymmetry, using the experimentally determined initial plate profiles and welding parameters for both Plate 1 and Plate 2 (see Table 2). Three different initial plate deformation profiles have been examined. Analyses have been performed where the initial plate profile has been assumed (i) initially undeformed (ii) taken to be the measured initial pre-tacked profile and (iii) the post-tack welded 
profile. In this case, the influence of initial distortion, asymmetry and welding parameters can be examined.

\subsection{Finite Element Meshes}

The weld region of the full mesh, the size of which is $10 \mathrm{~mm}$ which corresponds to experimental observations, consists of ten elements each $1 \mathrm{~mm}$ wide and $2.5 \mathrm{~mm}$ long as shown in Figure 5 . The degree of distortion predicted can be sensitive to the degree of mesh refinement. Convergence studies have shown $[4,20,21]$ that four elements through the thickness of the $4 \mathrm{~mm}$ plate, as modelled here, enable the distortions to be predicted accurately and efficiently. Furthermore, the solution's sensitivity to element type, mesh and specimen restraint has been examined prior to this study $[11,22]$ to provide a model of optimum computational time without compromise on accuracy. Complex details, such as the exact shape of the weld pool, which has some natural variability between welds, have not been modelled here for simplicity. Three dimensional, 20 noded continuum diffusive heat transfer elements (type DC3D20) have been employed in the thermal analyses. In the mechanical analysis, 3D continuum eight noded reduced integration elements (C3D8R) have been used [19] to prevent any issues with shear locking. The number of nodes and elements in each model are identified in Table 4.

\subsection{Thermal Analysis}

Within the FE analysis the form of the heat flux must be identified. A number of models are available to describe the shape of the heat source that represents the weld torch (see e.g. [23, 24]). A study has been performed to examine the influence of various heat source models on the predictions' accuracy. A simplified 2-D square cross-section heat source model has been found appropriate for this study on thin plates. This has the advantage that a fine mesh is not needed as would be in the case of a curved heat source, provided the correct heat quantity is maintained in each case. In this model, the distributed heat flux $q$ is described by,

$$
q=\eta V I / d^{2}
$$


where, $\eta$ is the thermal efficiency, $V$ is the weld torch voltage and $I$ is the current. The user subroutine DFLUX in ABAQUS [19] is used to introduce the surface heat flux described in Eqn (1). The subroutine first calculates the position of the weld torch according to the welding time, $t$, and the uniform weld velocity, $v$, and then calculates the heat flux, $q$, at each integration point. The size of the heat source, $d$, is taken to be $10 \mathrm{~mm}$ which corresponds to the weld width observed.

\subsection{Thermal-Mechanical Material Properties and Conditions}

Temperature dependent thermo-mechanical properties for $\mathrm{DH}-36$ steel [25] have been employed. The temperature dependency of the thermal conductivity and density are shown in Figure 6(a), the specific heat capacity in (b), elastic modulus and coefficient of thermal expansion in (c) and the constitutive relations are shown in Figure 6(d). Similar properties are exhibited by the weld metal and parent plate, as indicated in Figure 7 where the true stress at $0.2 \%$ true plastic strain are compared for the parent plate and weld material for a range of temperatures. Hence, in the absence of appropriate data for the weld material, parent material properties have been employed throughout. An isotropic hardening model can over-estimate hardening effects, and hence the residual stress, should cyclic hardening occur (by neglecting the Bauschinger effect and the plastic shakedown) whereas a kinematic law may underestimate hardening effects and exaggerate the Bauschinger effect. A combined kinematic/isotropic model may more accurately represent the material behaviour however, for simplicity, and considering only a single weld pass is made in this model, isotropic behaviour has been assumed. The material's microstructural evolution is likely to be a more significant effect than the hardening behaviour, however reasonable residual stress and distortion predictions can usually be found without directly modelling such complexities [3, 26]. The annealing temperature used was $850{ }^{\circ} \mathrm{C}$ which corresponds to the ferritic-austenitic phase transformation temperature. It is known that phase transformation can significantly affect the expansion coefficient, however for simplicity this effect has not been considered in this study. A detailed review on welding residual stress measurement and prediction methods are given in [27], where recommendations for mechanical simulations of welding processes are provided. 
The convective and radiative heat flux from the plates surfaces $q_{c o n v}$ and $q_{\text {rad }}$, respectively are determined using

$$
q_{\text {conv }}=h\left(T_{s}-T_{\infty}\right)
$$

and

$$
q_{\text {rad }}=\varepsilon \sigma_{S B}\left(T_{s}^{4}-T_{\infty}^{4}\right)
$$

where $h$ is the heat transfer coefficient, $\varepsilon$ is the emissivity of the surface, $\sigma_{S B}$ is the StefanBoltzman constant, $T_{s}$ the plate's surface temperature and $T_{\infty}$ the ambient temperature. The radiative and convective heat loss were modelled using the ${ }^{*}$ RADIATION and ${ }^{*}$ FILM options in ABAQUS. The values of $h$ and $\varepsilon$ are assumed temperature independent and constant. The initial temperature of the plate is set to $20^{\circ} \mathrm{C}$ and the ambient temperature is also assumed to be $20^{\circ} \mathrm{C}$. Radiative and convective thermal boundary conditions were applied to all surfaces except on any symmetry planes where adiabatic conditions apply. The convective heat transfer coefficient, $h$, emissivity, $\varepsilon$, and the thermal efficiency, $\eta$, given in Table 5 , have been established by matching the thermal analysis results to experimental measurements. The filler metal addition has not been modelled explicitly by, e.g. element rebirth or using a lumped enthalpy term during solidification as such effects are incorporated into the heat source term, as in $[4,24,29]$. The enthalpy change during the solid state phase transformation is modelled, Figure $6 \mathrm{~b}$, although rate effects on cooling are ignored.

The plates have been constrained only in order to prevent rigid body motion, by restraining translation and rotation about a point at the plate edge along the weld centre line (i.e. the point with co-ordinates $(0,0,0)$ is constrained in $x, y$ and $z$ directions, point $(0,4,0)$ in the $x$ direction and $(0,1000,0)$ is constrained in $x$ and $z$ directions). A non-linear geometry analysis (NLGEOM [19]) was performed such that the large distortions of the thin plates could be captured. 


\section{Simulation Results}

\subsection{FE Model Validation}

Residual stress measurements have been performed using the neutron diffraction technique on another butt welded plate that was nominally the same as Plate 1 and Plate 2 considered here. However, the welding parameters employed for this plate measured, which corresponded to the generic welding parameters shown in Table 2, differs somewhat, and the energy input per unit length falls between that of Plate 1 and Plate 2. These residual stress measurements have previously been presented in [16], and the FE predictions from a half symmetry model presented in [11]. Note that no initial distortion measurements were available for the plate on which residual stress measurements were performed. The through thickness range of stress predictions, using an initially undeformed full plate model and the generic welding parameters, are compared to the through thickness average residual stress measurements at the mid-length of the plate in Figure 8. The predicted stress values at the top, mid thickness and bottom of the plate are indicated in these figures. The stresses in the normal (out-of-plane) direction are relatively small in this thin plate, thus only stresses in longitudinal and transverse directions are shown. The fitting uncertainty of the measurements was around $20 \mathrm{MPa}$.

The FE predictions are in good agreement with the experimental measurements. There is some discrepancy within the weld itself and the heat affected zone (HAZ), i.e. within the weld zone $\pm 10 \mathrm{~mm}$ from the weld centre, which may be attributed to phase transformation and solidification effects. In practice the welding speed varies during the manual process employed, hence the energy input at the plate's mid-length, where the measurements were performed, may have been greater than the average energy input per unit length assumed in the FE model, leading to the wider tensile zone observed than that predicted, as identified in [30]. Tensile transverse stresses are predicted at the bottom of the plate in the vicinity of the weld which become compressive over $40 \mathrm{~mm}$ from the weld centre. The opposite trend is observed at the top of the plate, whereas the transverse stress are approximately constant and small at the mid thickness positions. Similarly the 
peak tensile longitudinal stresses are predicted to occur at the HAZ/Parent material interface adjacent to the weld bead at the bottom surface of the plate.

\subsection{Influence of Initial Plate Profile on Residual Stress and Distortions}

The influence of the initial plate profile alone on the final weld distortion profiles has been determined by simulating the butt welding procedure in the five symmetrical half models using uniform generic welding parameters, as identified in Table 2. Contour plots of the post-weld out-ofplane displacement resulting from simulations based on the initially distorted meshes (Plate 1a, 1b, $2 a$ and $2 b$ ) are shown in Figure $9(a)-(d)$ and compared to that of an initially flat plate (Plate $U$ ) in Figure $9(e)$. Note that the final plate profile will combine the initial plate profile and the post-weld out-of-plane displacement. The angular deformation, camber displacement and radius of curvature have been quantified where possible and are given in Table 6.

A noticeable effect of the initial plate profile has been observed on the post-weld out-of-plane displacement, particularly for Plate 1a (Figure 9a). The resultant post-weld out-of-plane displacement in Figure 9(b)-(d) are all positive and similar in form to the case where there is no initial distortion present in the plate (Figure 9e), i.e. contours of semi elliptical shape emanating from a position at the plates edge and mid length are observed. Large displacements of 22-23 mm in magnitude are predicted at the plates' edge. It can be deduced by comparing Figure 9 to Figure $3(a, b)$ that the area of this zone of large displacement tends to decrease with a decrease in the level of positive distortion initially present in the plate. The direction of the post-weld deformation follows the dominant direction of the initial imperfection. Hence, initial imperfections are often introduced into FE models to perturb the structure in the expected or desired buckling modes [19]. For plates $1 b, 2 a$ and $2 b$ the dominant imperfection is clearly positive. For plate $1 a$ however, which has a relatively large region of negative distortion at the plates centre and low positive distortion at the free edges (Figure 3a), the resultant post-weld out-of-plane displacements is in the negative $z$ direction and up to $16.6 \mathrm{~mm}$ in magnitude (Figure 9a). 
The residual stress distributions in the longitudinal direction for each of the initially distorted plates (Plate 1a, 1b, 2a and 2b) are compared to the distributions in an initially undeformed flat (Plate $U$ ) in Figure 10. These are the stresses along a path extending from the weld centre to the plate edge at the mid-length and mid-thickness of the plate. Note that the stresses predicted in the transverse and normal direction are very small in comparison to the longitudinal stress distribution, hence no variations can be observed unless the scales are significantly exaggerated, which may be misleading. Hence, the stresses in the transverse and normal direction are not shown here. The longitudinal stresses are almost identical for up to $40 \mathrm{~mm}$ from the weld centre, beyond which a maximum difference of around $40 \mathrm{MPa}$ is observed between the stress magnitudes in each plate. Plates $2 \mathrm{a}$ and $2 \mathrm{~b}$, which initially had a positive distortion along this line $(y=500 \mathrm{~mm})$, have similar values and show the highest tensile stresses in the far field region away from the weld. The results for Plates $1 \mathrm{a}$ and $1 \mathrm{~b}$, which initially had a generally negative distortion in this region fall close to that of Plate $U$ which was initially flat.

\subsection{Simulated Welding Profiles in Full Asymmetric Plates}

\subsubsection{Thermal Profiles}

The thermal profiles predicted in Plate 2, were compared to the thermocouple measurements at distances of $\pm 12 \mathrm{~mm},-7.5 \mathrm{~mm}$ and $+7 \mathrm{~mm}$ from the weld centre and are illustrated in Figure 11 . Note that negative distances correspond to side $a$, and positive distances to side $b$. The measured and predicted results are in good agreement and are symmetrical about the weld centreline, thus in Figure 11 only one set of measurements are shown for $\pm 12 \mathrm{~mm}$ from the weld centre. A peak temperature of over $1250^{\circ} \mathrm{C}$ and $1050^{\circ} \mathrm{C}$ is exhibited at $7 \mathrm{~mm}$ and $-7.5 \mathrm{~mm}$, respectively, from the weld, indicating the sensitivity to small changes in positioning accuracy of the thermocouples and/or welding torch, as previously realised (see e.g. [27, 31]). A detailed review and comparison of transient thermal profile measurement and prediction techniques is given in [27]. 


\subsubsection{Predictions of Post Welding Distortion}

The post weld out-of-plane displacement predictions in Plate 1 and Plate 2 are shown in Figure 12 based on $(a, b)$ an undeformed initially flat plate profile $(c, d)$ the measured pre-tack initial profiles and $(e, f)$ the measured tack welded plate profiles. Note that unlike the results shown in Figure 9 , which was based on a symmetric model and generic weld properties, the actual measured welding parameters and full asymmetric distortion profile for both plates 1 and 2 are modelled here. All predicted displacements are in the positive $z$ direction, and greatest in the region of the peak initial distortion. The energy input per unit length for Plate 2 was over $20 \%$ higher than that in Plate 1 (see Table 2) which has led to $2 \mathrm{~mm}$ higher peak displacements in Plate $2(23.0 \mathrm{~mm})$ compared to Plate $1(21.0 \mathrm{~mm})$, as can be seen in Figure 12(a,b). This was due to variations in the welding speed, Table 2, in the manual conditions employed. It has been predicted that, when joined, sides $a$ and $b$ of Plate 1 have displaced in a similar manner based on the plates pre-tack profile, Figure 12(c), though side $b$ has experienced a larger displacement (up to $23.0 \mathrm{~mm}$ ), resulting from the higher initial positive distortions in this side of the plate (see Figure 3a). The peak displacement predicted based on the post-tack weld's initial profile in Plate $1(33.7 \mathrm{~mm}$ in Figure 12e) is over $10 \mathrm{~mm}$ greater than that based on the initial plate's profile, resulting from the variation in their initial values of over $6 \mathrm{~mm}$. A relatively symmetric displacement is observed, following the relatively symmetric initial post tack profile. Similar trends are found for Plate 2. However, larger displacements are predicted in Plate 2 compared to Plate 1, in this case largely resulting from the higher energy input per unit length of weld.

The final distortion patterns (i.e. the combination of a plate's initial distortion and post weld displacement), are shown in Figure 13 based on the plates' measured (a, b) pre-tack initial profile and (c, d) post tack welded plate profile. Note that predictions for the case of an initially flat plate are not shown in Figure 13 since the post weld distortion is identical to the post weld displacement (Figure 2a, b) in this case. The distortion angle predicted in both plates based on the undeformed, pre- and post-tack weld initial plate profile have been quantified where possible and are given in Table 3. 
A complex distortion profile is predicted for Plate 1, as shown Figure (a), resulting from the asymmetry and complexity of the plate's initial profile, however based on the post-tack weld profile, a relatively symmetric profile results in Figure 13(c). The resultant distortion modes predicted for Plate 2, based on the pre- and post-tack initial distortion profile Figure 13 (b) and (d), respectively, are similar to that of an initially undeformed plate (Figure 12b). By comparing Figure 13(c, d) to (a, b), respectively, it can be deduced that the initial distortion profile has a significant effect (over to $10 \mathrm{~mm}$ ) on the final distortion magnitudes. Compared to the measured distortions (Figure 3f) similar distortion modes are predicted for Plate 2 side b, however the measured level of distortion lies between that predicted based on the pre- and post-tack initial distortion profile.

\subsubsection{Residual Stress Predictions}

The sensitivity of the residual stress predictions to the initial profile has been examined. The residual stress distributions predicted based on the initially undeformed $(U)$ and post-tack welded distortion profile are shown as an example of the extreme case considered, for both Plate 1 and Plate 2 in Figure 14 A small degree of asymmetry in the residual stress profiles are observed which can promote buckling (see e.g. [17]), however this may be considered negligible. By comparing the results of Plate $1 U$ and $2 U$, it can be seen that for this case the variation in residual stress due to the higher heat input per unit length of Plate 2 is small in comparison the differences due to the plates initial profiles. However, a distinct influence on the distortion of these two plates has been noted (see Table 3). The higher magnitude, asymmetric distortion profiles in the post-tack welded profiles of Plate 1 and Plate 2 have led to more notable variations in the residual stress profiles in Figure 14, compared to that based on symmetrical models as seen in Figure 10.

\section{Discussion}

It is clear that significant distortions can exist in unwelded base plates which can influence the final plate distortion profile and have some effect on the residual stress distributions. The models presented here have avoided detailed complexities that are related to the welding procedure. 
Further considerations include the influence, location and sequence of tack welds and the out-ofplane forces required to align initially distorted plates prior to tacking.

The tack welds are re-fused during the main welding procedure, and hence preliminary studies have indicated that their influence on final residual stresses may not be significant. Neutron diffraction measurements on unwelded base plates have revealed that small regions of considerable residual stresses at the edges of the plates (due to e.g. laser cutting) have no influence on the final residual stresses in butt welded plates since they become part of the main weld [16]. However, tack welds are known to influence distortions. Tack welds restrain in-plane motion until they are released through melting. Experimental studies in [32] have shown that where there is initial distortion in the plates, the release of tacks and the redistribution of weight on the supports has led to buckling and the reversal of deformation patterns. Tack sequencing is considered to have relatively little influence on the distortions, however studies in [32] have shown that the placement of tacks on the top surface of the plate promotes angular deformation in the upwards direction and vice versa.

Overall, therefore, the models predict and experiments confirm that the initial distortion profile, and that arising from tacking, can have a significant influence on the final distortion of the weldment. However, the magnitude of the maximum out-of-plane displacements is over predicted by the present model. Presumably this is because in the simulation, the two plates being welded are assumed to be intimately joined prior to the thermo-mechanical process, whereas in the real situation opening and closing of the weld gap between the tacks occurs, which in some cases can even break the tack welds. This effect could be incorporated in the simulations by explicitly modelling the filler metal addition, e.g. using the element rebirth technique $[19,33]$. The tack welding process itself could also be incorporated explicitly and the distortion produced modelled. In the present work, this effect is only considered as an input parameter via the distortions produced. However, a sufficiently complex model has been presented here that establishes the influence of initial plate distortion on final post-weld distortion profiles and residual stress distributions. 
Another important factor, not studied here, is the influence of supports and clamping. In this study, rigid body motions were prevented using appropriate boundary conditions at points located at both edges at the centre of the plates $(x=0, y=0$ and $y=1000 \mathrm{~mm})$. These boundary conditions have however prevented the upward, out-of-plane motion at the weld centre shown experimentally (see Figure 3e) for Plate 1. Work has been performed to consider the influence of boundary conditions on distortion profiles (see e.g. [11, 32]). However, further work is required to develop the optimal set of boundary conditions that enable the required deformation modes to be considered when the plates are initially distorted, as in the current FE model.

\section{Conclusions}

The influence of pre-existing deformation on the final residual stress distribution and distortion profile on thin $(1 \mathrm{~m} \times 1 \mathrm{~m} \times 4 \mathrm{~mm})$ butt welded plates of $\mathrm{DH}-36$ steel has been examined. The initial plate profiles have been measured experimentally and incorporated into finite element models of welding. Complex, non-linear surface profiles with considerable out-of-plane deformations of up to $10 \mathrm{~mm}$ have been measured in the base plates prior to welding. The direction of the post-weld deformation follows the dominant direction of the initial imperfection. A region of positive initial distortion in the plates is found to promote further displacement in that direction, and vice versa. Finite element analyses have revealed that the relatively small variations in the residual stress distributions of plates welded under identical conditions must be attributed to the initial plates' distortion. A degree of asymmetry in the distortion and residual stress distributions has resulted from initially asymmetrically distorted plates. The FE prediction of the final distortion mode resembled that measured experimentally for the case of the plate with least initial distortion. It is considered that further analyses are required that incorporate the influence of tack weld restraint and boundary conditions in addition to the initial plate distortion in order to fully capture the distortion modes observed experimentally. 


\section{Acknowledgements}

The authors would like to acknowledge Dr Martyn Lightfoot of Newcastle University for the provision of the experimental distortion data and Dr Norrie McPherson of BAE Systems, Govan, Scotland, UK for provision of welding facilities and materials. Funding was supplied via EPSRC grants EP/D060729/1, GR/T26344/01 and EP/H004882/1.

\section{References}

[1] M. J. Bibby, J. A. Goldak, and G. Y. Shing, G.Y. A Model for Predicting the Fusion and HeatAffected Zone Sizes of Deep Penetration Welds. Can. Metall. Q., 24, 1985, p 101-105.

[2] L. E. Lindgren, and L. Karlsson, Deformations and Stresses in Welding of Shell Structures. Int. J. Numer. Methods Eng., 25, 1988, p 635-655.

[3] S. Oddy, J. A. Goldak, and J. M. J. McDill, Transformation Plasticity and Residual Stresses in Single-Pass Repair Welds. J. Pressure Vessel Technol. 114, 1992, p 33.

[4] D. Dye, O. Hunziker, S. M. Roberts, and R. C. Reed,. Modeling of the Mechanical Effects Induced by the Tungsten Inert-Gas Welding of the IN718 Superalloy. Metall. Trans. A, 32, 2001, p. 1713-1725.

[5] Z. Sadovský, A. P. Teixeira, and C. Guedes Soares, Degradation of the Compression Strength of Square Plates due to Initial Deflection. J. Constr Steel Res., 62, 2006, p 369-377.

[6] W. Cui, and A. E. Mansour, Effects of Welding Distortions and Residual Stresses on the Ultimate Strength of Long Rectangular Plates under Uniaxial Compression. Marine Structures 11, 1998, p 251-269.

[7] L. Gardner, and D. A. Nethercot, Numerical Modeling of Stainless Steel Structural Components - A Consistent Approach. J. Struct. Div., Am. Soc. Civ. Eng. 130, 2004, p 1586-1601.

[8] F. Mateus, and J. A. Witz, A Parametric Study of the Post-Buckling Behaviour of Steel Plates. Engineering Structures, 23, 2001, p 172-185.

[9] Y. P. Yang, and F. W. Brust, Weld Modeling of Thin Structures with VFT Software, Jul 25-29, 2004 (San Diego), ASME Pressure Vessels Piping Conf., Proc., 2004, San Diego, p 99-107. 
[10] P. Mollicone, D. Camilleri, and T. Gray, Procedural influences on non-linear distortions in welded thin-plate fabrication. Thin Walled Struct., 46, 2008, p 1021-1034.

[11] M. Tsunori, C. M. Davies, D. Dye, and K. M. Nikbin, Numerical Modelling of Residual Stress and Distortion in Thin Welded Steel Plates, Jun 27-31, 2008 (Illinois), ASME Pressure Vessels Piping Conf., Proc., 2008, Illinois, p 299-307.

[12] M. P. Lightfoot, N.A. McPherson, K. Woods, and G. J. Bruce, Artificial Neural Networks as an Aid to Steel Plate Distortion Reduction. J. Mater. Process. Technol., 172, 2006, p 238-242.

[13] E. Røed, Certified Material Tests Report. Norsk Sveiseteknikk AS, Norway, 2006.

[14] V. Lexhas, Inspection Certificate. DUFERCO CLABECQ SA, Belgium, p. Certificate Number ANT : 0500001/0500474, 2006.

[15] M. M. Goldan, As-built product modeling and reverse engineering in shipbuilding through combined digital photogrammetry and CAD/CAM technology. J Ship Prod 19, 2003, p 98-104.

[16] C. M. Davies, R. C. Wimpory, M. Béreš, M. P Lightfoot, D. Dye, E. Oliver, N. P. O'Dowd, and J. G. Bruce, The Effect of Residual Stress and Microstructure on Distortion In Thin Welded Steel Plates, Jul 22-26, 2007 (Texas), ASME Pressure Vessels Piping Conf., Proc., 2007, Texas, p 851-858

[17] T. D. Huang, P. Dong, L. A. DeCan, and D. D. Harwig, 2003. Residual stresses and distortions in lightweight ship panel structures. Technol. Rev. J., 11, 2003, p 1-26.

[18] N. A. McPherson, Thin Plate Distortion Reduction - a Management or Technology Issue?, Weld. Cutting, 5, 2006, p 277-282.

[19] ABAQUS, Analysis User's Manual v 6.6. ABAQUS, Inc, 2006.

[20] H. J. Stone, S. M. Roberts, and R. C. Reed, A process model for the distortion induced by the electron-beam welding of a nickel-based superalloy. Metall. Trans. A, 31A, 2000, p 2261-2273.

[21] S. A. Tsirkas, P. Papanikos, and T. Kermanidis, Numerical simulation of the laser welding process in butt-joint specimens. J. Mater. Process. Technol. 134, 2003, p 59-69. 
[22] H. Murkawa, M. Béreš, C. M. Davies, S. Rashed, A. Vega, M. Tsunori, K. M. Nikbin, and D. Dye, Effect of Low Transformation Temperature Weld Filler Metal on Welding Residual Stress. Sci. Technol. Weld. Joining , 15, 2010, p 393-399.

[23] J. Goldak, and A. Chakravarti, M. Bibby, New Finite Element Model for Welding Heat Sources. Metall. Trans. B, 15(2), 1984, p 299-305.

[24] L. E. Lindgren, Finite Element Modeling and Simulation of Welding. Part 2: Improved Material Modeling. J. Therm. Stresses, 24(3), 2001, p 195-231.

[25] N. A. McPherson, Personnal communication. BVT Surface Fleet Ltd, 2008.

[26] L. E. Lindgren, Finite Element Modeling and Simulation of Welding Part 1: Increased Complexity. J. Therm. Stresses, 24(2), 2001, 141-192.

[27] M. C. Smith, and A. C. Smith, NeT Bead-on-Plate Round Robin: Comparison of Residual Stress Predictions and Measurements. Int. J. Pressure Vessels Piping, 86, 2009, p 79-109.

[28] H. Murakawa, M. Béreš, A. Vega, S. Rashed, C. M. Davies, D. Dye, and K. M. Nikbin, Effect of Phase Transformation onset Temperature on Residual stress in Welded Thin Steel Plates, Trans. JWRI, 37, 2008, p 75-80.

[29] R. V. Preston, H. R. Shercliff, P. J. Withers, and S. Smith, S., Physically-Based Constitutive Modelling of Residual Stress Development in Welding of Aluminium Alloy 2024. Acta Mater., 52, 2004, p 4973-4983.

[30] C. M. Davies, M. Béreš, D. Hughes, D. Dye, and K. M. Nikbin, The Influence of Geometric and Welding Parameters on Residual Stress in Thin Welded Steel Structures, Jul 26-30, 2009 (Prague), ASME Pressure Vessels Piping Conf., Proc., 2009, Prague, p 327-334

[31] X. Shan, C. M. Davies, T. Wangsdan, N. P. O'Dowd, and K. M. Nikbin, Thermo-Mechanical Modelling of a Single-Bead-on-Plate Weld using the Finite Element Method. Int. J. Pressure Vessels Piping, 86, 2009, p 110-121.

[32] P. Mollicone, D. Camilleri, T. Gray, and T. Comlekci, Simple thermo-elastic-plastic models for welding distortion simulation. J. Mater. Process. Technol. 176, 2006, p 77-86. 
[33] M. Abid, and M. Siddique, M, Numerical simulation to study the effect of tack welds and root gap on welding deformations and residual stresses of a pipe-flange joint. Int. J. Pressure Vessels Piping., 82, 2005, p 860-871. 


\section{Figure Captions}

Figure 1: Illustration of the set-up for welding.

Figure 2: Illustration of typical weld distortion modes in a butt welded plate defining the parameters used to quantify distortion.

Figure 3: Experimentally measured distortion in Plate 1 and Plate $2(a, b)$ prior to tack welding, (c, d) post tack welding and (e, f) after butt welding of the plates.

Figure 4: Initial camber distortion along the edges $(x= \pm 502 \mathrm{~mm})$ of both sides of Plate 1 and Plate 2 (a) prior to and (b) after tack welding.

Figure 5: Illustration of the top and side views of the FE mesh.

Figure 6: The temperature dependency of the physical and thermo-mechanical material properties (a) thermal conductivity and density (b) specific heat capacity, (c) elastic modulus and thermal expansion coefficient and (d) tensile data.

Figure 7: Comparison of true stress at $0.2 \%$ true plastic strain measured during compression tests in the parent plate and weld metal material at a range of temperatures [28].

Figure 8: Comparison of the neutron diffraction measurements (points) to the FE model residual stress predictions (band) in the (a) longitudinal and (b) transverse directions. The measurements are an average over a gauge volume centred in the middle of the plate and the FE model's predicted variation through the thickness is shown.

Figure 9: Comparison of the post weld out-of-plane displacement for (a) Plate 1a, (b) Plate 1b, (c) Plate 2a, (d) Plate $2 b$ and (e) a plate with no initial distortion.

Figure 10: Comparison of the longitudinal residual stress predictions in Plate 1a, 1b, 2a, 2b and Plate $U$ with no initial distortion.

Figure 11: Example comparison of measured and simulated temperature distributions in Plate 2 at distances of, $7 \mathrm{~mm}$ and $-7.5 \mathrm{~mm}$ and $12 \mathrm{~mm}$ from the weld centre.

Figure 12: Predicted out of plane displacements after butt welding in Plate 1 and Plate 2 based on $(a, b)$ undeformed initial (flat) plate profile (c, d) initial (pre-tack) measured distortion profile (e, f) measured post-tack welding distortion profile (contour interval $=2 \mathrm{~mm}$ ). 
Figure 13: Final distortion profile predictions (i.e. the combination of the plates' initial distortion and post weld displacement) after butt welding in Plate 1 and Plate 2 based on the measured initial (a, b) pre-tack and (c, d) post-tack post-tack welding distortion profile (contour interval $=2 \mathrm{~mm}$ ).

Figure 14: Comparison of the residual stresses predicted, at the mid-length and thickness of Plate 1 and Plate 2 in the longitudinal direction, assuming an initially undeformed $(U)$ and the post-tack weld profile.

\section{Table Captions}

Table 1: Chemical composition (\% wt) of DH-36 steel plate [14] and the NST MC-1 weld wire [13]. Table 2: Summary of the welding parameters employed

Table 3: The measured and predicted angular distortion, $\alpha$, at the mid-length $(y=500 \mathrm{~mm})$, weld start $(y=0 \mathrm{~mm})$ and end positions $(y=1000 \mathrm{~mm})$, the radius of curvature, $R$, and the maximum camber displacement, $\hat{z}$, for (a) Plate 1 and (b) Plate 2.

Table 4: Summary of mesh details

Table 5: Summary of parameters for the thermal analysis

Table 6: Angle and radius of curvature predicted in the symmetric weld model using the generic weld parameters. 
Figure 1

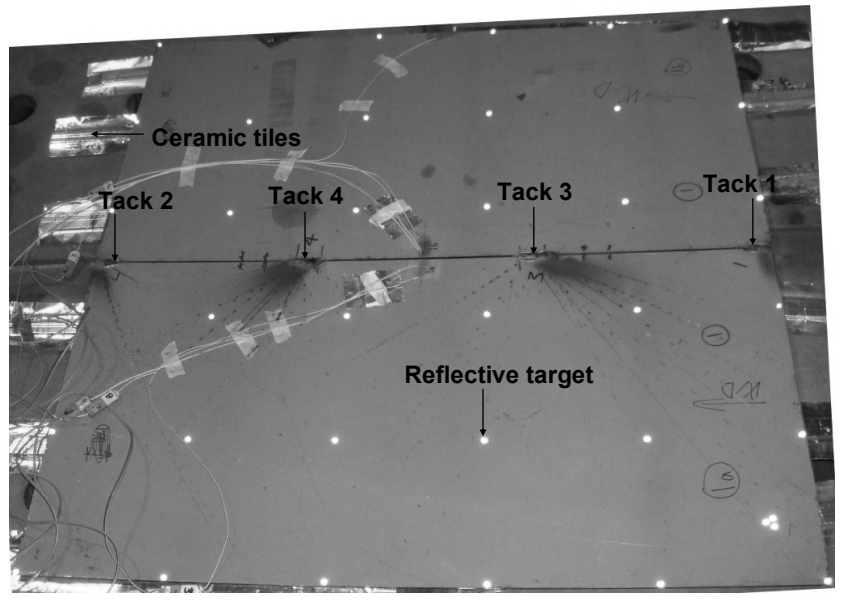

Figure 1: Illustration of the set-up for welding. 
Figure 2

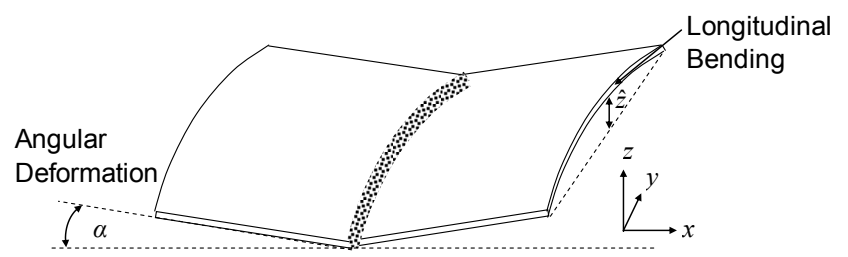

Figure 2: Illustration of typical weld distortion modes in a butt welded plate defining the parameters used to quantify distortion. 
Figure 3
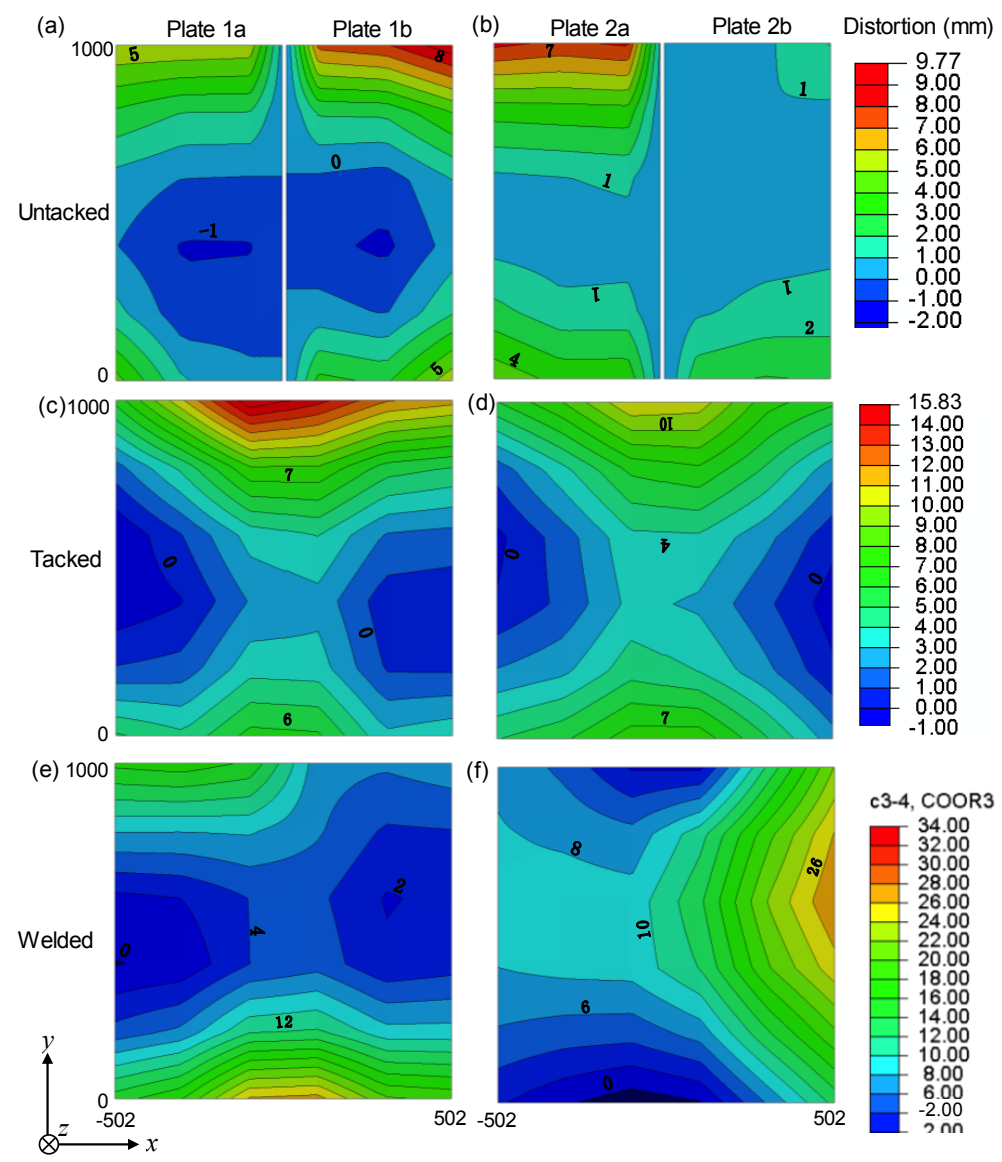

Figure 3: Experimentally measured distortion in Plate 1 and Plate $2(a, b)$ prior to tack welding, (c,

d) post tack welding and (e, f) after butt welding of the plates. 


\section{Figure 4}
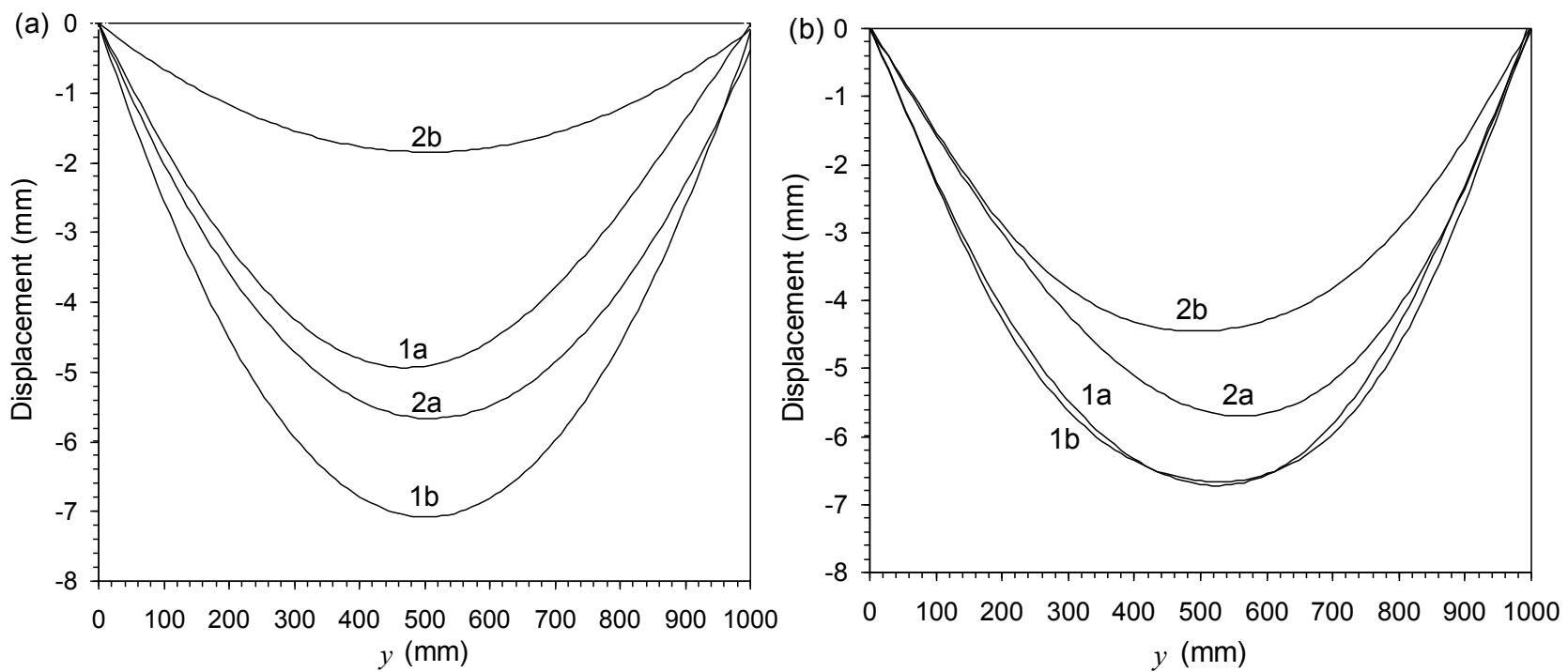

Figure 4: Initial camber distortion along the edges $(x= \pm 502 \mathrm{~mm})$ of both sides of Plate 1 and

Plate 2 (a) prior to and (b) after tack welding. 
Figure 5

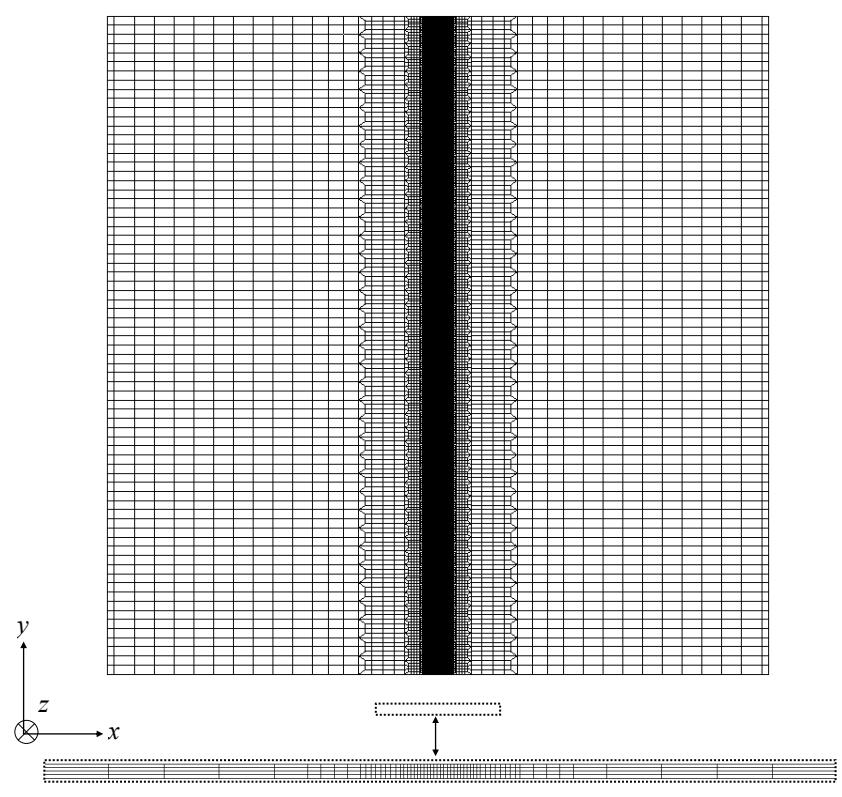

Figure 5: Illustration of the top and side views of the FE mesh. 
Figure 6
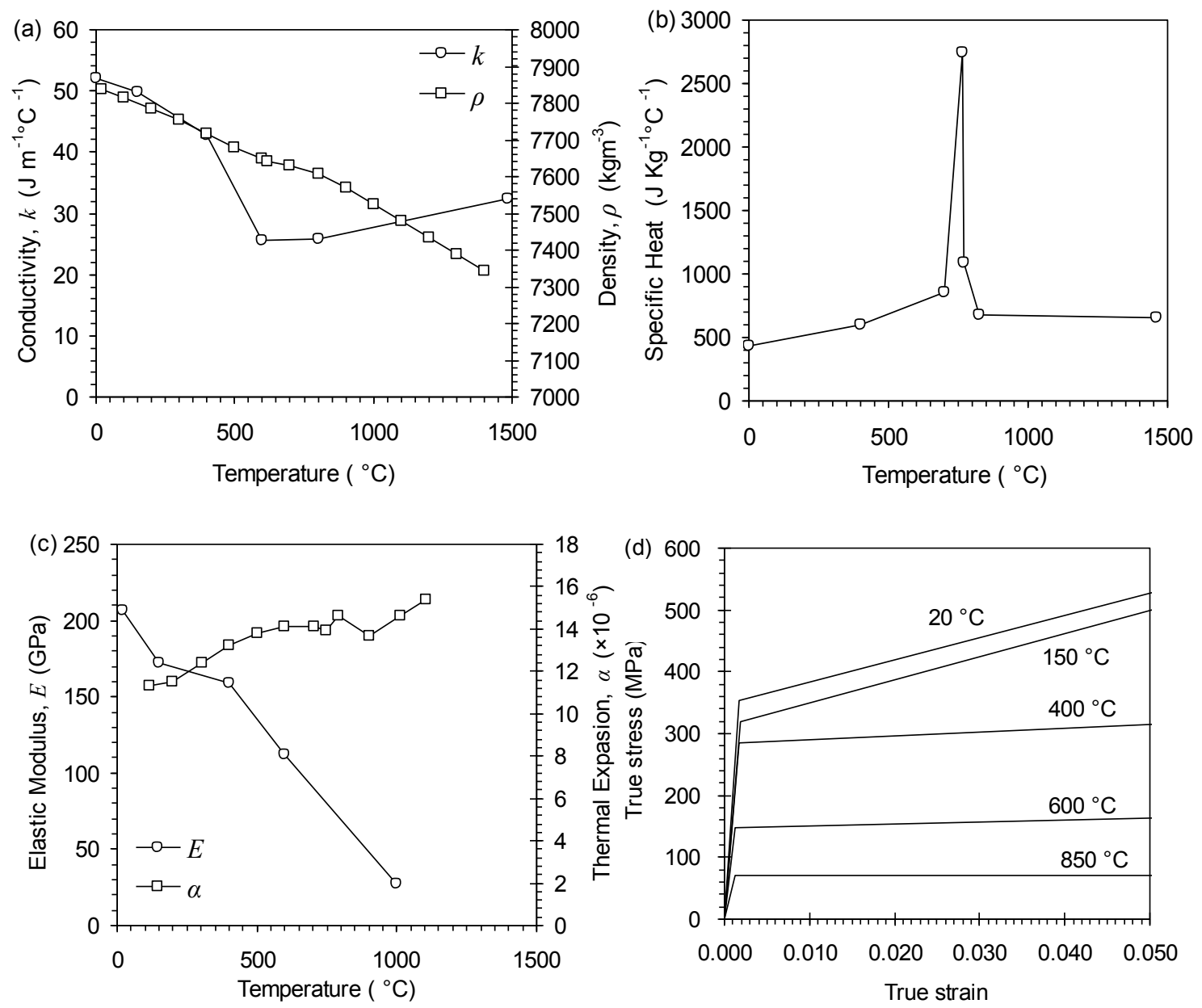

Figure 6: The temperature dependency of the physical and thermo-mechanical material properties

(a) thermal conductivity and density (b) specific heat capacity, (c) elastic modulus and thermal expansion coefficient and (d) tensile data. 
Figure 7

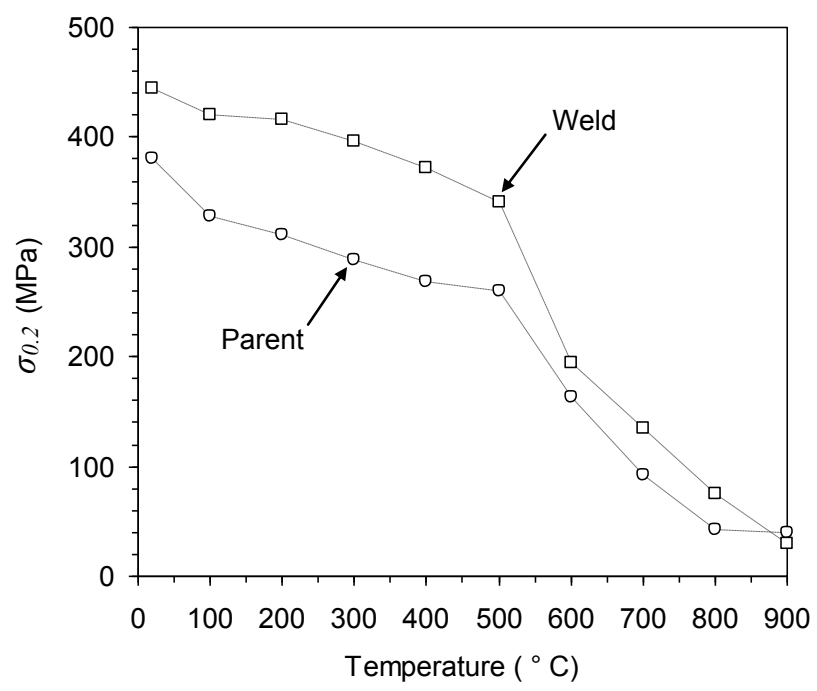

Figure 7: Comparison of true stress at $0.2 \%$ true plastic strain measured during compression tests in the parent plate and weld metal material at a range of temperatures [28]. 


\section{Figure 8}
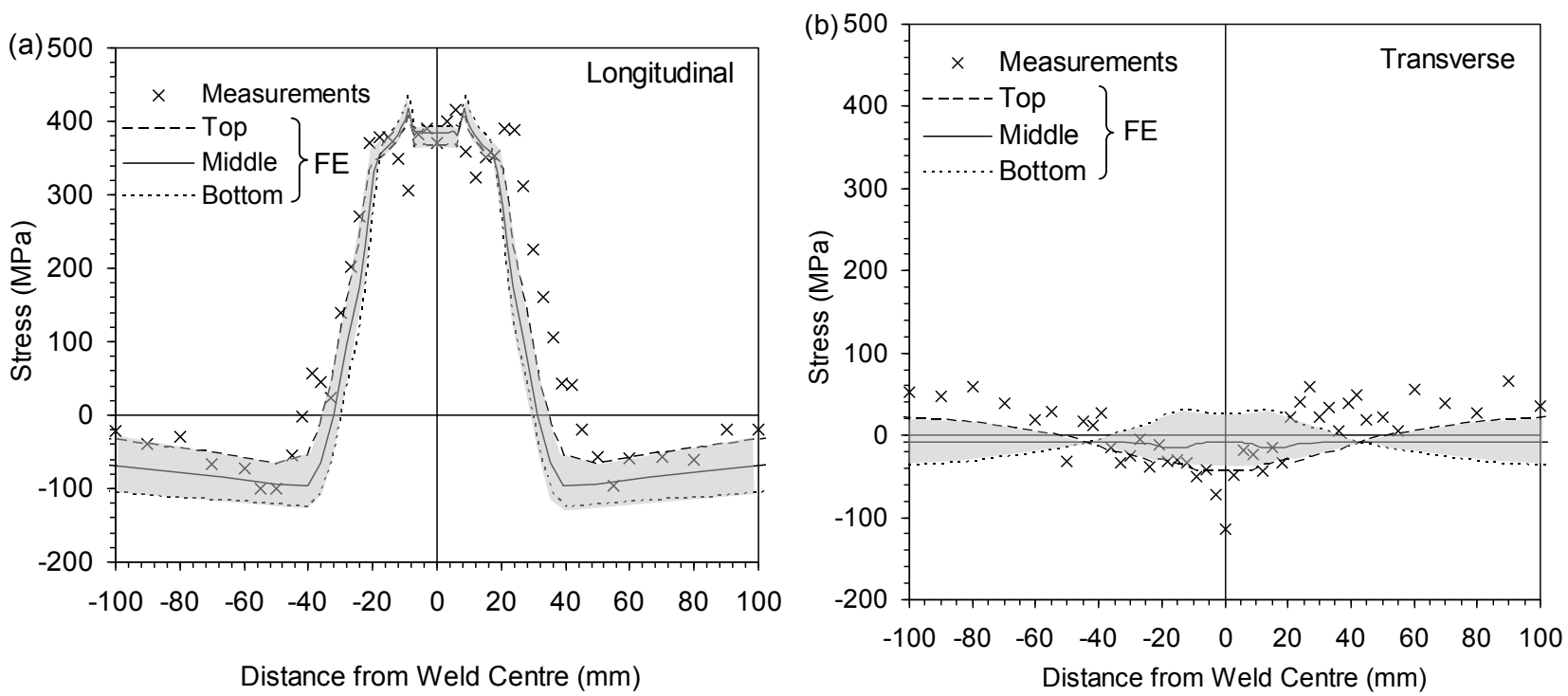

Figure 8: Comparison of the neutron diffraction measurements (points) to the FE model residual stress predictions (band) in the (a) longitudinal and (b) transverse directions. The measurements are an average over a gauge volume centred in the middle of the plate and the FE model's predicted variation through the thickness is shown. 


\section{Figure 9}

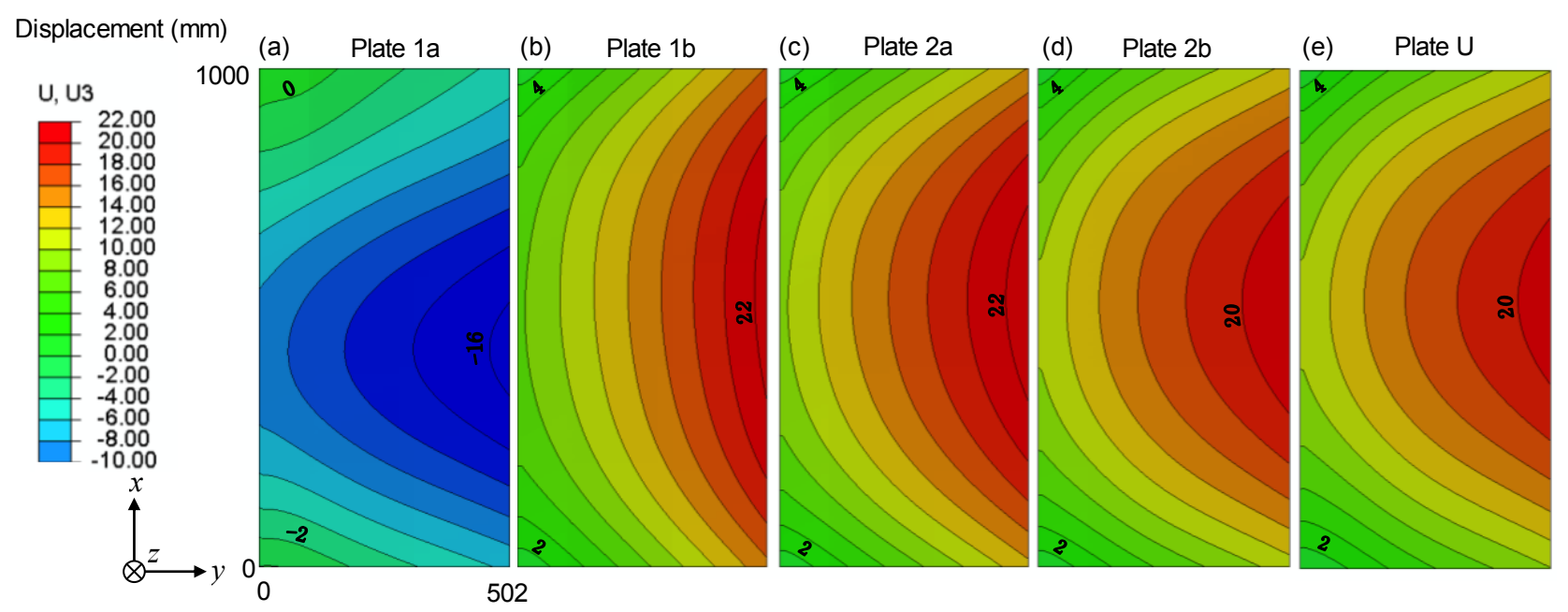

Figure 9: Comparison of the post weld out-of-plane displacement for (a) Plate 1a, (b) Plate 1b, (c)

Plate 2a, (d) Plate 2b and (e) a plate with no initial distortion. 
Figure 10

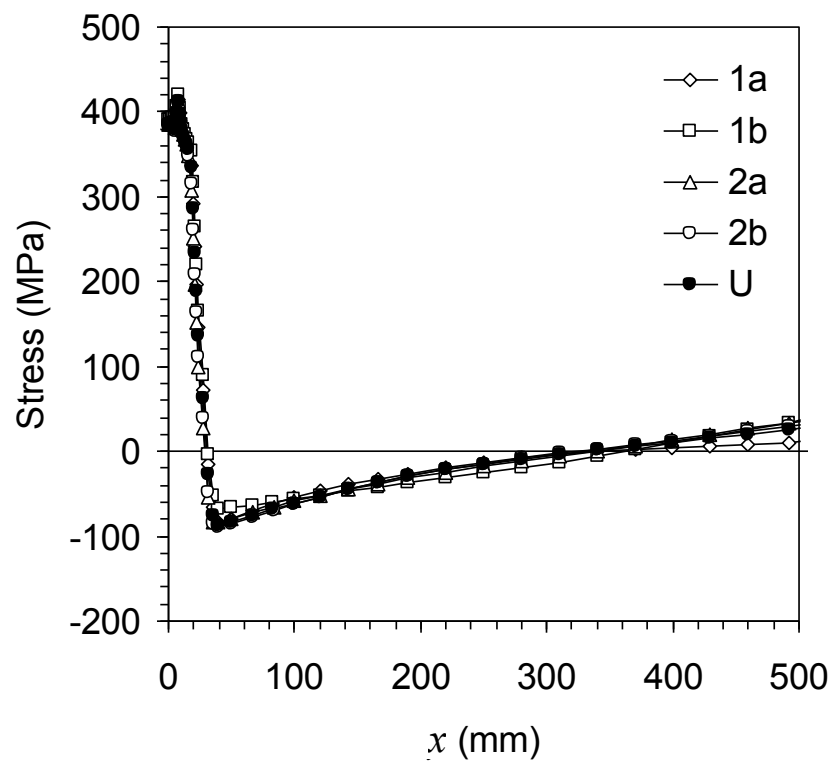

Figure 10: Comparison of the longitudinal residual stress predictions in Plate $1 a, 1 b, 2 a, 2 b$ and Plate $U$ with no initial distortion. 
Figure 11

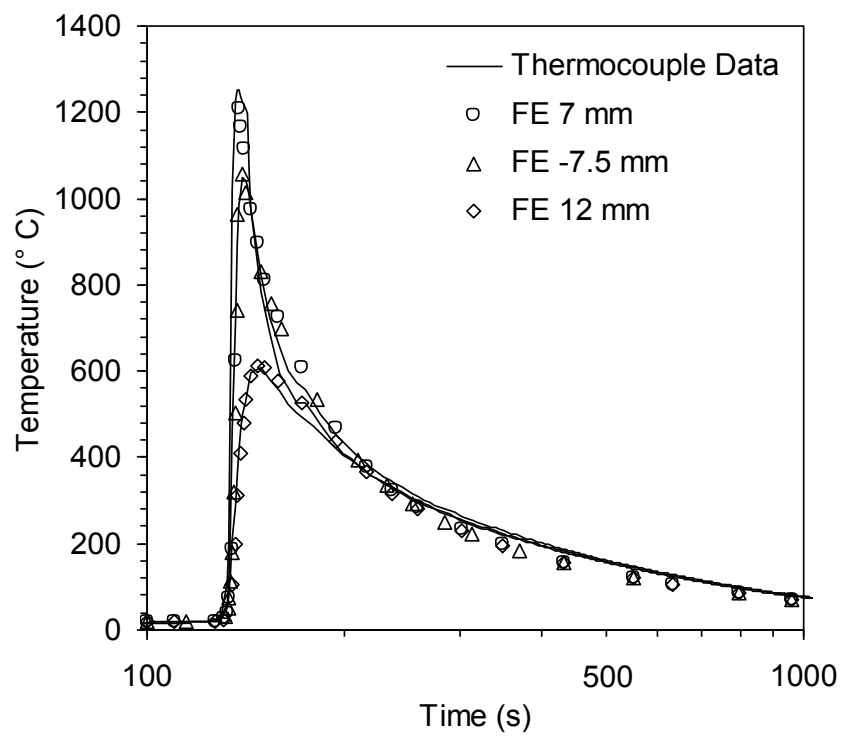

Figure 11: Example comparison of measured and simulated temperature distributions in Plate 2 at distances of, $7 \mathrm{~mm}$ and $-7.5 \mathrm{~mm}$ and $12 \mathrm{~mm}$ from the weld centre. 
Figure 12

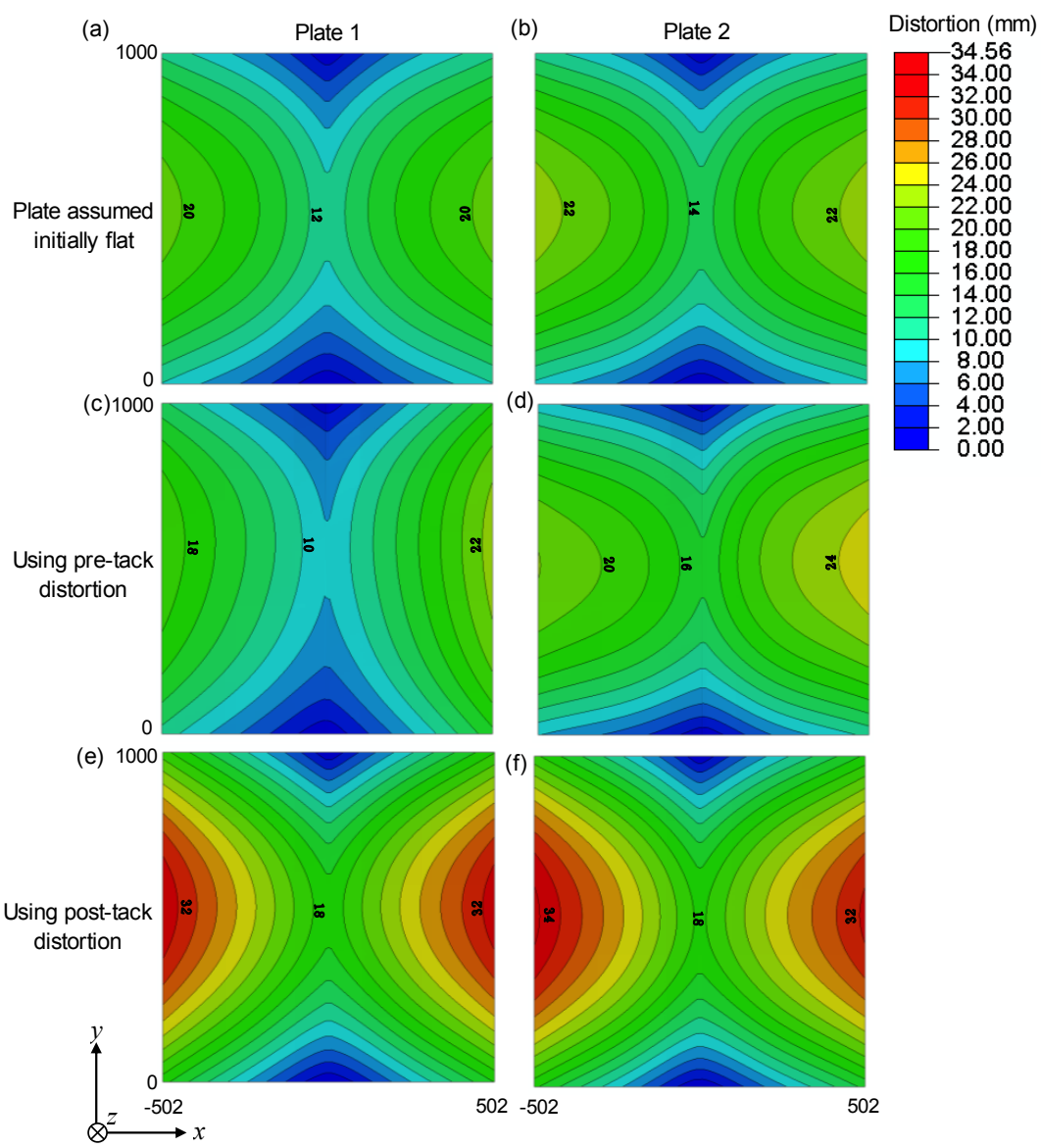

Figure 12: Predicted out of plane displacements after butt welding in Plate 1 and Plate 2 based on (a, b) undeformed initial (flat) plate profile (c, d) initial (pre-tack) measured distortion profile (e, f) measured post-tack welding distortion profile (contour interval $=2 \mathrm{~mm}$ ). 
Figure 13

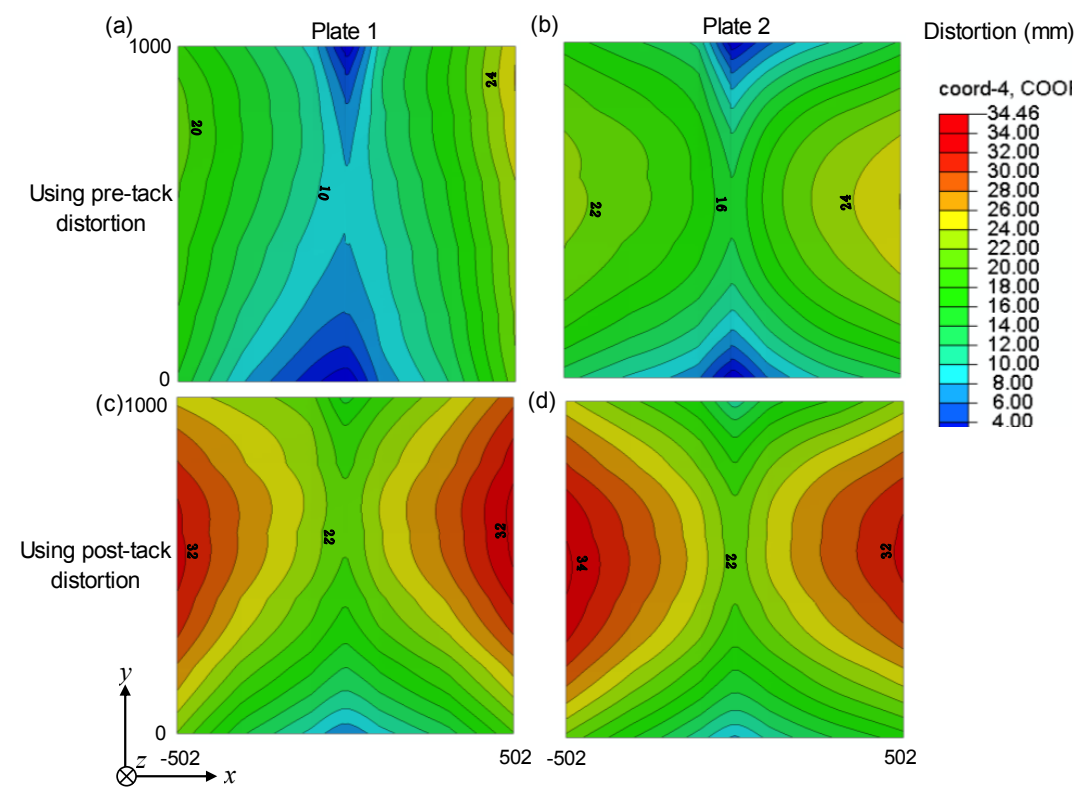

Figure 13: Final distortion profile predictions (i.e. the combination of the plates' initial distortion and post weld displacement) after butt welding in Plate 1 and Plate 2 based on the measured initial (a, b) pre-tack and (c, d) post-tack post-tack welding distortion profile (contour interval $=2 \mathrm{~mm}$ ). 
Figure 14

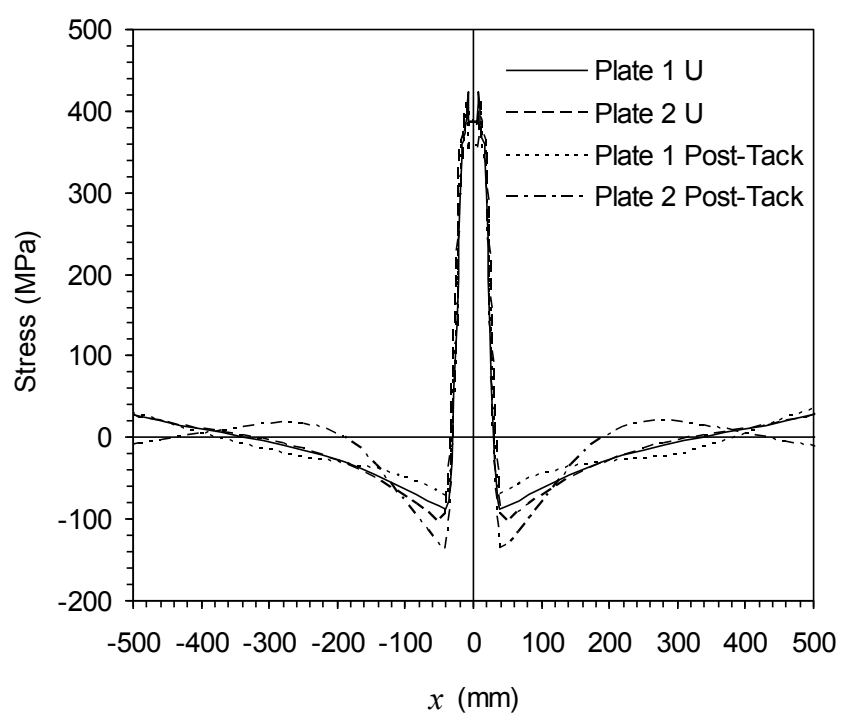

Figure 15: Comparison of the residual stresses predicted, at the mid-length and thickness of Plate 1 and Plate 2 in the longitudinal direction, assuming an initially 


\section{Table 1}

Table 1: Chemical composition (\% w.t.) of DH-36 steel plate [14] and the NST MC-1 weld wire [13].

\begin{tabular}{cccccccccc}
\hline & $\mathrm{C}$ & $\mathrm{Si}$ & $\mathrm{Mn}$ & $\mathrm{P}$ & $\mathrm{S}$ & $\mathrm{Cu}$ & $\mathrm{Ni}$ & $\mathrm{Cr}$ & $\mathrm{Nb}$ \\
\hline $\mathrm{DH}-36$ & 0.11 & 0.181 & 1.29 & 0.014 & 0.004 & 0.023 & 0.029 & 0.025 & 0.013 \\
Steel & & & & & & & & & \\
\hline Weld & 0.07 & 0.609 & 1.421 & 0.012 & 0.011 & 0.137 & 0.035 & 0.021 & 0.017 \\
Wire & & & & & & & & & \\
\hline
\end{tabular}


Table 2

Table 2: Summary of the welding parameters employed

\begin{tabular}{cccccc}
\hline & $\begin{array}{c}\text { Speed } \\
\left(\mathrm{mms}^{-1}\right)\end{array}$ & $\begin{array}{c}\text { Current } \\
(\mathrm{A})\end{array}$ & $\begin{array}{c}\text { Voltage } \\
(\mathrm{V})\end{array}$ & $\begin{array}{c}\text { Power } \\
(\mathrm{W})\end{array}$ & $\begin{array}{c}\text { Heat input } \\
\left(\mathrm{Jmm}^{-1}\right)\end{array}$ \\
\hline Plate 1 & 4.57 & 22 & 180 & 3960 & 867 \\
Plate 2 & 3.69 & 22 & 180 & 3960 & 1073 \\
Generic & 3.20 & 21 & 150 & 3150 & 984 \\
\hline
\end{tabular}




\section{Table 3}

Table 3: The measured and predicted angular distortion, $\alpha$, at the mid-length $(y=500 \mathrm{~mm})$, weld start $(y=0 \mathrm{~mm})$ and end positions $(y=1000 \mathrm{~mm})$, the radius of curvature, $R$, and the maximum camber displacement, $\hat{z}$, for (a) Plate 1 and (b) Plate 2.

\begin{tabular}{|c|c|c|c|c|c|c|c|c|c|c|c|}
\hline \multirow{2}{*}{\multicolumn{2}{|c|}{ Plate 1}} & \multicolumn{5}{|c|}{ Side a } & \multicolumn{5}{|c|}{ Side $\mathbf{b}$} \\
\hline & & \multirow{2}{*}{$\begin{array}{c}\alpha \\
(y=0) \\
\left({ }^{\circ}\right)\end{array}$} & \multirow{2}{*}{$\begin{array}{c}\alpha \\
(y=500) \\
\left({ }^{\circ}\right)\end{array}$} & \multirow{2}{*}{$\begin{array}{c}\alpha \\
(y=1000) \\
\left({ }^{\circ}\right)\end{array}$} & \multirow{2}{*}{$\begin{array}{c}\hat{z} \\
(\mathrm{~mm})\end{array}$} & \multirow{2}{*}{$\begin{array}{c}R \\
(\mathrm{~m})\end{array}$} & \multirow{2}{*}{$\begin{array}{c}\alpha \\
(y=0) \\
\left({ }^{\circ}\right)\end{array}$} & \multirow{2}{*}{$\begin{array}{c}\alpha \\
(y=500) \\
\left({ }^{\circ}\right)\end{array}$} & \multirow{2}{*}{$\begin{array}{c}\alpha \\
(y=1000) \\
\left({ }^{\circ}\right)\end{array}$} & \multirow{2}{*}{$\begin{array}{c}\hat{z} \\
(\mathrm{~mm})\end{array}$} & \multirow{2}{*}{$\begin{array}{c}R \\
(\mathrm{~m}) \\
\end{array}$} \\
\hline & lel / Plate Description & & & & & & & & & & \\
\hline \multirow{3}{*}{ 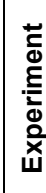 } & Initial Profile & $0.94^{*}$ & $0.24^{*}$ & $0.03^{*}$ & -5.00 & 101 & $0.77^{*}$ & $0.46^{*}$ & $0.55^{\star}$ & -7.1 & 70.0 \\
\hline & Tacked Profile & $-0.52^{*}$ & $-0.60^{*}$ & $-1.35^{\star}$ & -6.81 & 73.4 & $-0.45^{\star}$ & $-0.60^{*}$ & $-0.57^{*}$ & -6.7 & 74.7 \\
\hline & Welded Profile & $-2.20^{*}$ & $-0.74^{*}$ & $-0.62^{*}$ & -15.70 & 31.8 & $-1.60^{*}$ & $-0.67^{*}$ & 0.08 & -11.4 & 44.0 \\
\hline \multirow{3}{*}{ 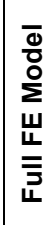 } & $\begin{array}{l}\text { Undeformed Initial } \\
\text { Profile }\end{array}$ & 1.13 & 1.19 & 1.31 & 10.3 & 48.5 & 1.13 & 1.19 & 1.31 & 10.3 & 48.5 \\
\hline & $\begin{array}{l}\text { Asymmetric, Untacked } \\
\text { Initial profile }\end{array}$ & 1.79 & 1.33 & $1.34^{*}$ & 0.90 & 151 & 2.41 & 1.78 & $2.12^{*}$ & 3.3 & $-{ }^{\dagger}$ \\
\hline & $\begin{array}{l}\text { Asymmetric, Tacked } \\
\text { Initial profile }\end{array}$ & 1.79 & 1.49 & 1.15 & 15.8 & 31.7 & 1.55 & 1.65 & 1.62 & 9.5 & 52.5 \\
\hline
\end{tabular}

\begin{tabular}{|c|c|c|c|c|c|c|c|c|c|c|c|}
\hline \multirow[t]{2}{*}{ (b) } & \multirow[t]{2}{*}{ Plate 2} & \multicolumn{5}{|c|}{ Side a } & \multicolumn{5}{|c|}{ Side $b$} \\
\hline & & \multirow{2}{*}{$\begin{array}{c}\alpha \\
(y=0) \\
\left({ }^{\circ}\right)\end{array}$} & \multirow{2}{*}{$\begin{array}{c}\alpha \\
(y=500) \\
\left({ }^{\circ}\right)\end{array}$} & \multirow{2}{*}{$\begin{array}{c}\alpha \\
(y=1000) \\
\left({ }^{\circ}\right)\end{array}$} & \multirow{2}{*}{$\begin{array}{c}\hat{z} \\
(\mathrm{~mm})\end{array}$} & \multirow{2}{*}{$\begin{array}{l}R \\
(\mathrm{~m})\end{array}$} & \multirow{2}{*}{$\begin{array}{c}\alpha \\
(y=0) \\
\left({ }^{\circ}\right)\end{array}$} & \multirow{2}{*}{$\begin{array}{c}\alpha \\
(y=500) \\
\left({ }^{\circ}\right)\end{array}$} & \multirow{2}{*}{$\begin{array}{c}\alpha \\
(y=1000) \\
\left({ }^{\circ}\right)\end{array}$} & \multirow{2}{*}{$\begin{array}{c}\hat{z} \\
(\mathrm{~mm})\end{array}$} & \multirow{2}{*}{$\begin{array}{c}R \\
(\mathrm{~m})\end{array}$} \\
\hline Moc & del / Plate Description & & & & & & & & & & \\
\hline \multirow{3}{*}{ 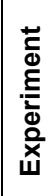 } & Initial Profile & $0.30^{*}$ & -0.02 & $0.15^{\star}$ & -6.10 & 83.0 & 0.04 & 0.03 & $0.37^{*}$ & -1.80 & 273.0 \\
\hline & Tacked Profile & -0.36 & -0.50 & -0.70 & -5.79 & 86.3 & -0.74 & -0.44 & $-0.88^{*}$ & -4.47 & 111.8 \\
\hline & Welded Profile & 0.51 & 0.09 & 0.81 & 3.60 & 140.0 & 1.83 & 1.92 & 2.80 & 9.60 & 52.0 \\
\hline \multirow{3}{*}{ 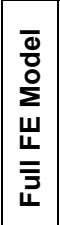 } & $\begin{array}{l}\text { Undeformed Initial } \\
\text { Profile }\end{array}$ & 1.09 & 1.15 & 1.28 & 12.74 & 39.3 & 1.09 & 1.15 & 1.28 & 12.74 & 39.3 \\
\hline & $\begin{array}{l}\text { Asymmetric, Untacked } \\
\text { Initial Profile }\end{array}$ & 2.16 & 1.7 & $1.69^{*}$ & 7.9 & 41.0 & 2.07 & 1.85 & 2.14 & 12.1 & 64.0 \\
\hline & $\begin{array}{l}\text { Asymmetric, Tacked } \\
\text { Initial Profile }\end{array}$ & 1.51 & 1.48 & 1.45 & 11.5 & 43.6 & 1.01 & 1.24 & 1.25 & 12.5 & 39.9 \\
\hline
\end{tabular}

\footnotetext{
${ }^{*}$ the maximum value of $\alpha$ is given for the cases where a unique value of $\alpha$ could not be quantified due to complex, non-linear plate profiles.
} 


\section{Table 4}

Table 4: Summary of mesh details

\begin{tabular}{cccc}
\hline Model & Number of & Number of & Number of \\
& Elements & Nodes & Nodes \\
& & DC3D20 & C3D8R \\
\hline Half, Symmetry Model & 45,600 & 220,515 & 58,400 \\
Full Model & 91,200 & 435,422 & 114,795 \\
\hline
\end{tabular}




\section{Table 5}

Table 5: Summary of parameters for the thermal analysis

\begin{tabular}{ccc}
\hline$\eta(\%)$ & $h\left(\mathrm{Wm}^{-2}{ }^{\circ} \mathrm{C}^{-1}\right)$ & $\varepsilon$ \\
\hline 60 & 10 & 0.4
\end{tabular}




\section{Table 6}

Table 6 Angle and radius of curvature predicted in the symmetric weld model using the generic weld parameters.

\begin{tabular}{lccccc}
\hline Plate No. & $\alpha(y=0)$ & $\alpha(y=500)$ & $\alpha(y=1000)$ & $R$ & $\hat{z}$ \\
& $\left({ }^{\circ}\right)$ & $\left({ }^{\circ}\right)$ & $\left(^{\circ}\right)$ & $(\mathrm{m})$ & $(\mathrm{mm})$ \\
\hline Plate 1a & $-0.63^{*}$ & -0.84 & $-0.78^{*}$ & 32 & -15.7 \\
Plate 1b & 2.42 & 1.80 & $2.14^{*}$ & $-{ }^{+}$ & 0.7 \\
Plate 2a & 2.07 & 1.63 & $1.55^{*}$ & 136 & 3.7 \\
Plate 2b & $1.20^{*}$ & 1.38 & $1.41^{*}$ & 61 & 15.7 \\
Plate U & 1.13 & 1.22 & 1.36 & 49 & 10.1 \\
\hline
\end{tabular}

* the maximum value of $\alpha$ is given for the cases where a unique value of $\alpha$ could not be quantified due to complex, non-linear plate profiles 